\title{
Part Two: Pharmacokinetic Evaluation of E-Liquid Flavors of Vuse Solo Electronic Nicotine Delivery System, An Unblinded, Parallel, Randomized Study To Assess Nicotine Uptake In Smokers
}

Kyung Soo Hong ( $\nabla$ hongk@rjit.com )

RAI Services Company, 401 N. Main Street, Winston-Salem

\section{Patricia DeLuca}

RAI Services Company, 401 N. Main Street, Winston-Salem

Tao Jin

RAI Services Company, 401 N. Main Street, Winston-Salem

Bobbette A. Jones

Retired employee of RAI Services company

\section{Paul Nelson}

Retired employee of RAI Services company

\section{Eckhardt Schmidt}

Reynolds American (United States)

\section{Elaine Round}

RAI Services Company, 401 N. Main Street, Winston-Salem

\section{Research Article}

Keywords: nicotine, flavor, randomized, delivery

Posted Date: December 8th, 2021

DOI: https://doi.org/10.21203/rs.3.rs-1061045/v1

License: (c) (1) This work is licensed under a Creative Commons Attribution 4.0 International License. Read Full License 


\section{Abstract}

This paper reports the findings of a randomized nicotine pharmacokinetic (PK) study of a closed electronic nicotine delivery system (ENDS). The study evaluated four flavor variants of Vuse Solo ENDS where subjects used their randomized investigational product (IP) for 10 minutes ad libitum and blood samples were collected for $\mathrm{PK}$ assessments that included maximum plasma nicotine concentration $\left(C_{\text {max }}\right)$ and area under the nicotine concentration-vs-time curve up to 60 minutes $\left(A U C_{\text {nic0-60 }}\right)$. Baselineadjusted mean $C_{\text {max }}$ ranged from 6.53 to $8.21 \mathrm{ng} / \mathrm{mL}$, and mean $A U C_{\text {nic0-60 }}$ ranged from 206.87 to $263.52 \mathrm{ng} * \mathrm{~min} / \mathrm{mL}$ for all ENDS IPs. Results for $C_{\max }$ and $A U C_{\text {nic0-60 }}$ values were consistent among the ENDS IP flavor variants tested and results indicate that flavors did not affect nicotine uptake in human subjects.

\section{Introduction}

Cigarette smoking is a leading cause of preventable premature death, and significantly increases the risk of developing lung cancer, heart disease, chronic bronchitis, chronic obstructive pulmonary disease and other serious diseases and adverse health conditions ${ }^{1}$. Whereas smoking conventional cigarettes requires combustion of tobacco, use of electronic nicotine delivery systems (ENDS) does not. ENDS were developed as potential reduced-harm alternative products for cigarette smokers. ENDS heat a nicotinecontaining solution (e-liquid), which results in the generation of an aerosol containing fewer and lower levels of toxicants than are found in cigarette smoke ${ }^{2,3}$, and reduced toxicant exposure to consumers who switch from cigarettes to ENDS ${ }^{4-9}$. Several public health authorities, such as Public Health England ${ }^{10}$, Royal College of Physicians ${ }^{11}$, and National Academies of Sciences, Engineering, and Medicine ${ }^{12}$, have recognized the potential public health benefit of current smokers switching to ENDS. A review by the National Academies of Sciences, Engineering and Medicine (NAS) concluded that "[t]he evidences about harm reduction suggests that across a range of studies and outcomes, e-cigarettes pose less risk to an individual than combustible cigarettes" 12 .

This publication is the second part of a three-part series describing the clinical assessment of Vuse Solo. The clinical studies included in this publication series describe the nicotine pharmacokinetics (PK) of Vuse Solo across four e-liquid flavors; an assessment of the abuse liability of Vuse Solo as compared to $\mathrm{CC}$ and a nicotine replacement therapy product ${ }^{13}$; and a study to assess whether use of Vuse Solo results in a reduction in exposure to harmful and potentially harmful constituents (HPHCs) after smokers are switched to the product for five days ${ }^{14}$.

This report presents findings from a clinical study that assessed nicotine PK parameters of Vuse Solo during and following short-term, ad libitum use of one of four flavor variants of Vuse Solo products by smokers and dual smokers/ENDS users. The e-liquid flavors included Original (tobacco flavor), Mint, Tropical and Fusion. The study was executed following the parallel-group study design in which subjects 
were randomized to a single product, and nicotine PK was evaluated during and after a 10 min ad libitum product use following a week of ambulatory product acclimation (at-home).

\section{Results}

\section{Study Population}

A total of 148 subjects were enrolled and randomized; All subjects were randomized to one of four Vuse Solo investigational products (IPs) and 122 (82.4\%) subjects completed all scheduled PK assessments. A total of 26 subjects (17.6\%) were randomized but terminated early from the study for reasons unrelated to study products. Of these 122 study completers, four subjects were excluded from the final PK analysis due to $C_{\text {max }}$ less than $1.0 \mathrm{ng} / \mathrm{mL}$, indicating the IP was used, but subjects did not use it appropriately during the product use period. Thus, 118 (96.7\% of study completers) subjects completed the study with evaluable PK data. The number of subjects who completed the study (and the associate percentage of completers with evaluable PK data) in each IP group are as follows: Original $(n=30,93.3 \%)$, Mint $(n=34$, $100 \%)$, Tropical $(n=29,96.5 \%)$, and Fusion $(n=29,96.5 \%)$.

The demographic and baseline characteristics of subjects are summarized in Supplementary Table S1. Subjects were generally male (55.4\%), white (56.8\%), and predominantly non-Hispanic (74.3\%). The mean age was 33.7 years. Subjects enrolled in the study included 135 smokers (91.2\%) and 13 dual smokers and ENDS users (8.7\%). Subjects reported a mean smoking duration of 18 years with a mean of 16 cigarettes per day.

\section{Product use}

ENDS product use, determined by volume of e-liquid used, was assessed over two IP use periods as a surrogate for product use and to evaluate how much e-liquid was used. The use periods included oneweek ambulatory (at-home) trial period and four 10-minute use periods per PK assessment. The differences between initial and final cartridge weights were calculated for both periods and results are shown in Table 1. 
Table 1

Vuse Solo e-liquid usage (grams) during the at-home trial and PK assessment periods

\begin{tabular}{|lllll|}
\hline \multicolumn{1}{|c}{ Original } & Mint & Tropical & Fusion \\
\hline At-home trial period & & & & \\
\hline Number of subjects & 35 & 39 & 38 & 36 \\
\hline Mean (SD) & 0.2101 & 0.1643 & 0.2082 & 0.2010 \\
& $(0.2517)$ & $(0.1728)$ & $(0.2339)$ & $(0.2296)$ \\
\hline Median (range) & 0.1029 & 0.1127 & 0.0912 & 0.1117 \\
& $(0-0.8062)$ & $(0-0.7862)$ & $(0-0.7154)$ & $(0-0.7360)$ \\
\hline Day 2 PK Assessment & & & & \\
\hline Number of subjects & 30 & 34 & 29 & 29 \\
\hline Mean (SD) & 0.0348 & 0.0318 & 0.0371 & 0.0357 \\
& $(0.0269)$ & $(0.0171)$ & $(0.0229)$ & $(0.0270)$ \\
\hline Median (range) & 0.0266 & 0.0293 & 0.0374 & 0.02980 \\
& $(0.0003-0.1120)$ & $(0.0097-0.0882)$ & $(0.0076-0.1052)$ & $(0.0002-0.1420)$ \\
\hline Abbreviation: SD = standard deviation. & & & \\
\hline
\end{tabular}

\section{Pharmacokinetic results}

As illustrated in Figure 1, baseline-adjusted plasma nicotine concentrations increased rapidly within 15 minutes of use for each of the ENDS IPs evaluated. Mean plasma nicotine concentrations declined to less than $6 \mathrm{ng} / \mathrm{mL}$ for all IPs by 60 minutes. Baseline-adjusted nicotine PK parameters are summarized in Table 2. Nicotine uptake during the first 15 minutes following the start of product use $\left(A U C_{\text {nic } 0-15}\right), C_{\max }$ $A U C_{\text {nic0-60 }}$ and the time to reach the maximum nicotine concentration $\left(T_{\max }\right)$ across the 60 -minute sampling period were similar for all ENDS e-liquid flavor variants (Table 2). 
Table 2

Plasma nicotine pharmacokinetic parameters across Vuse Solo variants

\begin{tabular}{|c|c|c|c|c|}
\hline $\begin{array}{l}\text { PK Parameters } \\
\text { Assessed }\end{array}$ & $\begin{array}{l}\text { Original } \\
(\mathrm{N}=28)\end{array}$ & $\begin{array}{l}\text { Mint } \\
(\mathrm{N}=34)\end{array}$ & $\begin{array}{l}\text { Tropical } \\
(\mathrm{N}=28)\end{array}$ & $\begin{array}{l}\text { Fusion } \\
(\mathrm{N}=28)\end{array}$ \\
\hline $\begin{array}{l}C_{\max }(\mathrm{ng} / \mathrm{mL}) \\
(95 \% \mathrm{Cl})\end{array}$ & $\begin{array}{l}6.91 \\
(5.49-8.70)\end{array}$ & $\begin{array}{l}6.53 \\
(5.26-8.10)\end{array}$ & $\begin{array}{l}8.21 \\
(6.87-9.81)\end{array}$ & $\begin{array}{l}6.67 \\
(5.20-8.56)\end{array}$ \\
\hline $\begin{array}{l}\text { AUC }_{\text {nic0-15 }} \\
\left(\mathrm{ng}^{\star} \mathrm{min} / \mathrm{mL}\right) \\
(95 \% \mathrm{Cl})\end{array}$ & $\begin{array}{l}56.19 \\
(42.85-73.69)\end{array}$ & $\begin{array}{l}63.36 \\
(50.64-79.27)\end{array}$ & $\begin{array}{l}76.28 \\
(63.38-91.81)\end{array}$ & $\begin{array}{l}56.15 \\
(43.81-71.97)\end{array}$ \\
\hline $\begin{array}{l}\text { AUC }_{\text {nico-60 }} \\
\left(\mathrm{ng}^{\star} \min / \mathrm{mL}\right) \\
(95 \% \mathrm{Cl})\end{array}$ & $\begin{array}{l}223.79 \\
(180.13- \\
278.03)\end{array}$ & $\begin{array}{l}215.37 \\
(175.92- \\
263.68)\end{array}$ & $\begin{array}{l}263.52 \\
(218.92- \\
317.20)\end{array}$ & $\begin{array}{l}206.87 \\
(156.70- \\
273.10)\end{array}$ \\
\hline $\begin{array}{l}\mathbf{T}_{\max }{ }^{*} \\
(\min ) \\
\text { (range) }\end{array}$ & $\begin{array}{l}11.00 \\
(5.0-60.0)\end{array}$ & $\begin{array}{l}11.00 \\
(3.0-30.0)\end{array}$ & $\begin{array}{l}11.00 \\
(3.0-30.4)\end{array}$ & $\begin{array}{l}11.00 \\
(3.0-30.0)\end{array}$ \\
\hline $\begin{array}{l}\text { PK Parameters } \\
{ }^{*} T_{\text {max }} \text { reported } \\
\text { Subjects with } C \\
\text { Abbreviations: } \\
\text { under the curve } \\
\text { exposure over } 6\end{array}$ & $\begin{array}{l}n \text { this table are } \\
\text { value, followed } \\
y / m L \text { were exclu } \\
\text { nce interval, } C_{m} \\
\text { e exposure over } \\
T_{\max }=\text { time to }\end{array}$ & $\begin{array}{l}\text { eline-adjusted } g \\
\text { he range for mir } \\
\text { maximum nico } \\
\text { minutes, } A U C_{\text {nic }} \\
\text { kimum nicotine }\end{array}$ & $\begin{array}{l}\text { letric mean valu } \\
\text { um and maximu } \\
\text { concentration, } \\
=\text { area under the } \\
\text { entration. }\end{array}$ & $\begin{array}{l}\text { except for } \mathrm{T}_{\max } \text {. } \\
\text { irve- } 15=\text { area } \\
\text { incotine }\end{array}$ \\
\hline
\end{tabular}

While this study was not designed to statistically compare flavors, two of the nicotine PK parameters, $\mathrm{C}_{\max }$ and $\mathrm{AUC}_{\text {nic0-60, }}$, were qualitatively assessed across the ENDS flavor variants to evaluate nicotine uptake across the e-liquid flavors. Notched box plots of baseline-adjusted $C_{\max }$ and $A U C_{n i c 0-60}$ are shown in Figures 2 and 3, respectively, to visually compare the distributions and point estimates in $\mathrm{C}_{\max }$ or $A U C_{\text {nic0-60 }}$ across the flavors. Overall, the nicotine uptake parameters $C_{\max }$ and $A U C_{\text {nic0-60 }}$ were similar for all tested Vuse Solo flavors. No evidence of statistically significant difference in median $\mathrm{C}_{\max }$ or $\mathrm{AUC}_{\text {nic0-60 }}$ was found among the four flavor variants, as the notches in Figures 2 or 3 overlap with each other. This suggests that flavors do not appear to impact nicotine uptake in our study population.

\section{Product Liking Results:}


Overall product liking (OPL) was assessed at the 13-minute timepoint during test sessions using an 11point numeric rating scale (NRS) and results are presented in Table 3. Mean OPL scores (SD) ranged from 5.3 (2.5) for the Mint flavor to 7.5 (1.9) for the Tropical flavor, and were 6.4 (2.5) and 6.0 (2.5) for the Original and Fusion flavors, respectively. Median values reflect a similar trend with the Mint flavor with the lowest score of 5.5 and the Tropical with highest score of 8.0, and both the Original and Fusion flavors with same median score of 7.0 .

Table 3

Summary of overall product liking scores

\begin{tabular}{|lllll|}
\hline Summary statistics & $\begin{array}{l}\text { Original } \\
(\mathbf{N}=\mathbf{3 5})\end{array}$ & $\begin{array}{l}\text { Mint } \\
\mathbf{( N = 3 9 )}\end{array}$ & $\begin{array}{l}\text { Tropical } \\
\mathbf{( N = 3 8 )}\end{array}$ & $\begin{array}{l}\text { Fusion } \\
\mathbf{( N = 3 6 )}\end{array}$ \\
\hline Number of subjects & 30 & 34 & 29 & 29 \\
\hline OPL Mean (SD) & $6.4(2.5)$ & $5.3(2.5)$ & $7.5(1.9)$ & $6.0(2.5)$ \\
\hline Median & 7.0 & 5.5 & 8.0 & 7.0 \\
\hline $\begin{array}{l}\text { Range: 0-10. Overall Product Liking (OPL) was measured on a numerical rating scale from 0 to 10, } \\
\text { with 0 = strongly dislike and 10 = strongly like. Abbreviations: SD = standard deviation. }\end{array}$ \\
\hline
\end{tabular}

\section{Adverse events}

Nine (6\%) of 148 subjects experienced nine adverse events during the study. Gastroesophageal reflux (one subject) and oropharyngeal pain (one subject) were each considered by the principal investigator (PI) to be possibly related and related to IP, respectively. All other adverse events were judged by the PI not to be related to an IP. All adverse events were of mild intensity except for moderate ocular hyperemia in one subject, which led to subject withdrawal from the study by the PI. No serious adverse events were reported.

\section{Discussion}

We evaluated PK parameters of four flavor variants of e-liquids used in Vuse Solo ENDS with 4.8\% (57 $\mathrm{mg} / \mathrm{mL}$ ) nicotine content by weight following an acute exposure in predominately ENDS naïve smokers. Our data showed that subjects achieved similar overall nicotine exposure ( $\left.\mathrm{UUC}_{\text {nic0-60 }}\right)$, maximum plasma nicotine concentrations $\left(C_{\max }\right)$, and time to maximum concentrations $\left(T_{\max }\right)$ while using one of the four flavor variants of Vuse Solo ENDS. Evaluation of PK parameters, $C_{\max }$ and $\mathrm{AUC}_{\text {nic0-60, showed similar }}$ nicotine uptake distribution patterns across all flavors variants with overlap of the $95 \%$ confidence intervals (Cls) around the medians in both $\mathrm{C}_{\max }$ and $\mathrm{AUC}_{\text {nic0-60 }}$ (illustrated as the notches in boxplots, Figures 2 and 3). In addition to the PK assessments, product liking (OPL) for each flavor was assessed at the 13-minute timepoint (Table 3).

As stated above, the results and distribution of baseline-adjusted $\mathrm{C}_{\mathrm{max}}$ were similar across flavor variants. By comparison, baseline-adjusted maximum nicotine concentrations $\left(C_{\max }\right)$ of Vuse Solo flavor variants 
in this study are higher (Table 2) than those previously reported by Stiles et. al. using Vuse Solo ENDS Original (tobacco) ${ }^{15}$ and Vuse Solo ENDS Menthol ${ }^{16}$; for reference, the $29 \mathrm{mg}$ nicotine e-liquid used in the Stiles et. al. papers corresponds to roughly the same nicotine concentrations ( $57 \mathrm{mg} / \mathrm{ml}$ or $4.8 \%$ ) as was used in the current study. It is important to note key differences among study designs of the abuse liability studies performed by the Stiles et. al. papers and the current study. The former studies utilized a crossover design (Williams design) and were conducted in an ambulatory setting. In contrast, our study utilized a parallel design in confinement. Both Stiles AL studies had approximately 7 days of at-home product acclimation as our study with instruction to use ENDS IP at least once but product use compliance was not assessed. In our study, subjects were told to use the ENDS IPs as often as they liked, and product use compliance was confirmed by weighing used cartridges at the end of the at-home trial period. Thus, differences in study design as well as level of familiarity with study products and general differences between study populations may account for variability among data reported. In a study to evaluate the abuse liability (AL) of ENDS in experienced ENDS users by Hajek and colleagues ${ }^{17}$, Vuse Solo Original $4.8 \%$ was evaluated as one of the ENDS comparators and the results demonstrated that Vuse Solo Original $4.8 \%$ users achieved baseline-adjusted $C_{\max }$ of $13.6 \mathrm{ng} / \mathrm{ml}$ ( $9.7 \mathrm{SD}$ ), which is higher than what was found in the current study, but still lower than the $C_{\max }$ reported for cigarettes $(17.9 \mathrm{ng} / \mathrm{ml}$ [16 SD]). In contrast, in an AL study of cigarette smokers conducted by Goldenson and colleagues ${ }^{18}$, the authors reported that Vuse Solo Original $4.8 \%$ had a baseline-adjusted $\mathrm{C}_{\max }$ of $6.8 \mathrm{ng} / \mathrm{ml}$, which was similar to our study findings, and lower than cigarette $C_{\max }(15.4 \mathrm{ng} / \mathrm{ml})$. Similarly, another $A L$ study by Campbell et. al., with a similar subject population as the current study, reported a mean baseline-adjusted $\mathrm{C}_{\text {max }}$ for Vuse Solo Original $4.8 \%$ as $5.48 \mathrm{ng} / \mathrm{mL}^{13}$. Additional results from other AL studies also suggest that experienced users of ENDS demonstrate higher nicotine uptake, compared to naïve ENDS users, but in general the $\mathrm{C}_{\max }$ following acute exposure to ENDS was less than that observed with smoking a cigarette, regardless of the ENDS use experience ${ }^{13,19-25}$.

As was the case with $C_{\text {max }}$, baseline-adjusted $A U C_{\text {nic0-60 }}$ results and their distribution were also similar across Vuse Solo flavor variants. There are limitations in comparing the overall nicotine exposure, $A U C_{n i c 0-60}$, between the current study against published works due to the differences in AUC calculations performed across studies based on the duration of observation ${ }^{15-17}$. Goldenson et al., in an AL study among cigarette smokers, reported a baseline-adjusted $A U C_{n i c 0-60}$ of $216 \mathrm{~min} * \mathrm{ng} / \mathrm{ml}$ for Vuse Solo Original $4.8 \%$, which is similar to the $\mathrm{AUC}_{\text {nic } 0-60}$ for Vuse Solo Original in this study of $223.79 \mathrm{~min} * \mathrm{ng} / \mathrm{ml}$ 18. Taken together, the PK findings from this reported study are in agreement with previously published data using Vuse Solo ENDS ${ }^{15-18}$.

In addition to PK assessments, subjects were also asked to rate OPL for the Vuse Solo flavor variants on an 11-point NRS. Subjects rated the Tropical flavor highest and rated the Mint flavor lowest with Original (tobacco) and Fusion flavors in-between (Table 3). These reported scores were consistent with published data. In two AL studies by Stiles et. al., subjects assessed product liking scores for two flavors (Vuse Original and Menthol) at multiple timepoints over six hours after start of ENDS use. In both studies by 
Stiles et. al., maximum PL scores $\left(E_{\text {max }}\right)$ for Vuse Solo Original and Menthol (36 mg/ml nicotine) were reported at 4.13 and 4.53, respectively ${ }^{15,16}$, compared to 6.4 and 5.3 for Vuse Solo Original and Mint $4.8 \%$ (57 mg/ml nicotine) reported in this study. Similarly, in the AL studies by Goldenson et. al., and Campbell et. al., where Vuse Solo Original 4.8\% was used as an ENDS comparator, mean maximum product liking scores were between 4.5 and 5 , and 5.56, respectively ${ }^{13,18}$.

Review of our data on e-liquid consumption measured by cartridge weight before and after PK test sessions in the context of OPL scores suggest some trends but failed to show a direct linear correlation. St. Helen and colleagues examined the impact of flavors (Strawberry vs. tobacco) on nicotine uptake and topography. The authors found no statistically significant differences in PK parameters and in puffing behavior and noted the need for further investigation ${ }^{26,27}$. Of note, these differences were seen in subjects who used fruity/sweet flavored e-liquids in their own ENDS products, suggesting potential subject bias towards flavors that resembled their usual flavors.

Similarly, in a topography study to assess the effect of flavor in regular smokers, Voos et al., concluded that the flavors used in their study delivered differential amounts of nicotine, potentially associated with product use topography, and differences in subjective effects are not solely a product of nicotine delivery, and recommended additional research ${ }^{28}$. In contrast, Cobb et. al., assessed subjective effects among young adult smokers using ENDS with three flavors (cream, tropical fruit and tobacco/menthol) at nicotine concentrations ranging from 0 to $36 \mathrm{mg} / \mathrm{ml}$ nicotine and concluded that e-liquid flavors did not appear to have significant impact on subjective effects ${ }^{29}$. Thus, the implications of overall product liking scores on both PK parameters and e-liquid consumption may require additional studies to further evaluate any potential relationship.

In our study, subjects were asked to familiarize themselves with ENDS products at home for one week prior to a PK test session, and the amount of e-liquid consumed was measured by differences in cartridges weights obtained before and after a week of at home use. We found that our subjects used approximately $10 \%$ of e-liquid by weight ranging from $0.16(+/-0.17) \mathrm{mg}$ to $0.21(+/-0.25) \mathrm{mg}$ across the four flavors (Table 1). These results were similar to e-liquid consumption observed on the first day of exclusive ENDS use in a biomarker of exposure study by Round and colleagues ${ }^{8}$ and suggests that our ENDS naïve subjects were sufficiently acclimated to ENDS IPs during their at-home trial period prior to the PK test sessions.

Our study had several strengths. First, we included a large sample size to reduce variability compared to previous ENDS nicotine PK studies ${ }^{23,30-34}$. In addition, our subjects were required to acclimate to ENDS for seven days to become familiar with ENDS products prior to confinement and PK test sessions. Subjects were also required to abstain from tobacco products for 12 hours prior to PK test sessions to ensure their blood nicotine concentrations were close to baseline prior to the start of product use. Furthermore, we collected blood samples at intervals that allowed characterization of nicotine PK following ad libitum ENDS exposure and the nicotine concentrations of blood samples were baselineadjusted to ensure more accurate results. 
Despite these strengths, the study had several limitations. Although we allowed participation of dual users, more than $98 \%$ of our subjects were exclusive cigarette smokers. As the prevalence of dual and poly use of multiple types of tobacco and nicotine products, such as ENDS or other non-combustible nicotine products, continues to increase, inclusion of a greater proportion of dual users of CC and ENDS in future studies may be useful to make study findings more applicable to current nicotine and tobacco users. Future studies may also benefit from cross-over designs to evaluate nicotine PK with multiple flavor variants to reduce inter-user variability. Lastly, for this study, subjects were allowed a 10-minute ad libitum use of the ENDS 15,16,24,28,33,34. We chose the duration of 10-minutes of ENDS use to align with an estimated duration to smoke a single CC. However, this study design element may be modified in the future studies to align more closely with historical data on the time it takes to smoke a single CC, as well as current data trends around ENDS topography. Moreover, other considerations might include current reports on the time for subjects to smoke a single CC $18,35,36$ or recent study designs which leverage a shorter ENDS use period 17,22,29,31,32,37-42.

In conclusion, the primary endpoints of this study, $\mathrm{C}_{\max }$ and $A U \mathrm{C}_{\text {nic0-60, }}$, were similar across all four flavors as evidenced by the overlap of $95 \%$ confidence intervals, suggesting that flavors are not significant factors in nicotine exposure in an acute exposure setting. The results of this study will add to the growing body of literature regarding the effects of flavors on nicotine delivery and uptake.

\section{Methods}

This study was a single-center study (ClinicalTrials.gov identifier: NCT03234010, 31/07/ 2017) designed to evaluate plasma nicotine uptake and overall product liking with use of four flavor variants of the Vuse Solo ENDS (Vuse Solo Original, Mint, Tropical and Fusion) in tobacco consumers who were exclusive smokers or dual users of cigarettes and ENDS. The study was completed at a single clinical research site (DaVita Clinical Research, Lakewood, CO) and was reviewed and approved by Chesapeake Institutional Review Board (Columbia, MD).

The target number of subjects to be randomized was 35 subjects per IP group ( 140 subjects in total) to allow for approximately a $15 \%$ attrition rate ( 5 subjects per IP group) with a goal of completing 30 subjects per IP group. Attempts were made to recruit 15-20\% African-Americans within each IP group in an effort to balance the study sample for the reported percentage of U.S. smokers who are African American ${ }^{1}$. During a screening visit, eligibility criteria were assessed to ensure that potential subjects met all criteria for inclusion and none of the exclusion criteria. Eligible subjects included male and female smokers, aged 21-60 years who self-reported smoking 10 or more cigarettes per day for at least the previous 6 months, or dual users who self-reported smoking 10 or more cigarettes per day for at least the previous 6 months, and using a nicotine-containing cig-a-like or tank-style ENDS at least weekly for at least the previous 3 months. Brief periods of abstinence longer than 30 days before screening were allowed at the discretion of the of the PI. Smoking history was confirmed at screening and reassessed on Study Day 1 with an expired carbon monoxide (ECO) assessment, and only subjects with ECO levels 
greater than $10 \mathrm{ppm}$ were eligible to participate in the study. Informed consent was obtained from all subjects before any study procedures were performed.

The study was conducted in accordance with the ethical standards in the Declaration of Helsinki, applicable sections of the United States Code of Federal Regulations, and ICH E6 Good Clinical Practice guidelines.

\section{Study Design}

The study was designed as a randomized, open-label, parallel-cohort study to assess nicotine uptake in human subjects following ENDS use. The study examined plasma nicotine PK parameters in Vuse Solo ENDS with four flavor variants: Original, Mint, Tropical and Fusion.

Each Vuse Solo cartridge consisted of a sealed unit containing $0.5 \mathrm{~mL}$ of e-liquid comprising $4.8 \%$ nicotine by weight [ $58 \mathrm{mg} / \mathrm{mL}$ ], propylene glycol, glycerin, flavorings, and water. The products were powered by a rechargeable power unit and included a heating element, microchips, and a sensor. Aerosol generation is activated by detection of a pressure differential within the ENDS product during puffing.

Subjects were given a 1-week at-home trial period to become familiar with the assigned Vuse IPs. Subjects were randomized to specific ENDS flavors and were provided two cartridges with instructions for use. Product use compliance was checked by weighing ENDS cartridges three times before and after use to a sensitivity of $1 \times 10^{-4}$ grams before and after the at-home trial period.

On Study Day 1, subjects arrived at the study site and began their check-in procedures prior to confinement. Subjects returned ENDS IP e-liquid cartridges from the at-home trial period to the site. Eligibility criteria were reconfirmed, and those who successfully completed all check-in procedures were confined to the study site for approximately 24 hours. Subjects were allowed to use their assigned IP ad libitum until the start of a mandatory 12-hour abstinence from tobacco and nicotine products.

On the morning of Study Day 2, each subject was given their assigned ENDS IP for use during the PK assessment. Subjects were then allowed to use the assigned ENDS IP ad libitum for 10 minutes $( \pm 10$ seconds). Start and stop times were documented. ENDS IP cartridges were weighed three times before and after use to a sensitivity of $1 \times 10^{-4}$ grams.

During the PK assessment, blood samples were collected and processed to plasma for nicotine measurements at the following time points relative to the start of IP use: $-5,-0.5,3,5,8,10,11,12,15,20$, 30 , and 60 minutes. The -0.5 min sample was used as the preferred baseline sample. All samples were collected, processed, and transferred to Celerion Global Bioanalytical Services (Lincoln, NE) for nicotine quantitation using a validated liquid chromatography tandem mass spectrometry method.

In addition to blood sample collection, subjects were required to provide an OPL score at 13 minutes after start of IP use on a numeric scale of 0 to 10 , with 0 corresponding to "strongly dislike," 5 corresponding to 
"neither like nor dislike", and 10 corresponding to "strongly like." Each subject was assessed for adverse events and vital signs, and a symptom-driven physical examination was performed, if necessary, prior to discharge from the study to ensure subject's safety. Upon the Pl's review of subjects' status, if there were no new adverse events or physical examination findings to warrant further follow up, subjects were discharged from the study.

\section{Statistical Analysis}

The primary PK parameters $\left(\mathrm{C}_{\text {max }}, \mathrm{AUC}_{\text {nic0-60 }}\right)$ were summarized using descriptive statistics by IP group without inter-group comparisons. Standard summary statistics for quantitative and qualitative variables were calculated.

The pharmacokinetic (PK) analyses were performed by Nuventra Pharma Sciences, Inc. located in Durham, NC. PK parameters were derived from the baseline-adjusted plasma nicotine concentrations-time data by noncompartmental methods using Phoenix ${ }^{\circledR}$ WinNonlin ${ }^{\circledR}$ (Version 6.3; Certara USA Inc., Princeton, $\mathrm{NJ}$ ).

AUCs were calculated using the linear trapezoidal rule. $\mathrm{C}_{\max }$ and $\mathrm{T}_{\max }$ were obtained directly from the baseline-adjusted plasma nicotine concentration-time data. Observed concentrations below the lower limit of quantification (LLOQ; $0.200 \mathrm{ng} / \mathrm{mL}$ ) were set at half the LLOQ for data summarization and analysis. Baseline adjustment was done by estimating and subtracting pre-existing nicotine levels from observed levels, and all PK parameters were calculated from the adjusted concentrations. The amount of pre-existing nicotine was estimated by using a model that assumed that nicotine elimination followed first-order kinetics ${ }^{43,44}$ and a nicotine half-life of 120 minutes ${ }^{23,35,45}$. Each individual PK profile was examined for completeness and suitability for inclusion in the analysis. Subjects with $\mathrm{C}_{\max }$ values less than $1.0 \mathrm{ng} / \mathrm{mL}$ were considered to be not inhaling aerosol during the 10-minute period of ad libitum IP use; therefore, sensitivity analyses excluding those subjects were performed.

\section{Declarations}

\section{Acknowledgements}

The authors wish to acknowledge Megan J. Whelen and Sarah Baxter-Wright for medical writing assistance, critical review, and editing of the manuscript; Gregory P. Tarleton, MD for providing medical expertise to ensure subject safety; and Jeff Coffield for maintaining the study Trial Master Files and managing other study-related documentation.

\section{Author Contributions}

Study concept and design: K.S.H; P.D., B.A.J., E.R., P.N.

Acquisition of data: E.S. 
Drafting of the manuscript: K.S.H.

Critical revision of the manuscript for important intellectual content: All authors

Statistical analysis: T.J.

All authors have read and approved the final manuscript.

\section{Competing Interests Statement}

All authors are full-time or former employees of RAI Services Company. RAI Services Company is a wholly owned subsidiary of Reynolds American Inc., which is a wholly owned subsidiary of British American Tobacco plc.

\section{References}

1. In The Health Consequences of Smoking-50 Years of Progress: A Report of the Surgeon General Reports of the Surgeon General (2014)

2. Goniewicz, M. L., Kuma, T., Gawron, M., Knysak, J. \& Kosmider, L. Nicotine levels in electronic cigarettes. Nicotine Tob Res, 15, 158-166 https://doi.org/doi:10.1093/ntr/nts103 (2013).

3. Tayyarah, R. \& Long, G. A. Comparison of select analytes in aerosol from e-cigarettes with smoke from conventional cigarettes and with ambient air. Regul Toxicol Pharmacol, 70, 704-710 https://doi.org/doi:10.1016/j.yrtph.2014.10.010 (2014).

4. Cravo, A. S. et al. A randomised, parallel group study to evaluate the safety profile of an electronic vapour product over 12 weeks. Regul Toxicol Pharmacol, 81 Suppl (1), S1-S14 https://doi.org/doi:10.1016/j.yrtph.2016.10.003 (2016).

5. D'Ruiz, C. D., Graff, D. W. \& Robinson, E. Reductions in biomarkers of exposure, impacts on smoking urge and assessment of product use and tolerability in adult smokers following partial or complete substitution of cigarettes with electronic cigarettes. BMC Public Health, 16, 543 https://doi.org/doi:10.1186/s12889-016-3236-1 (2016).

6. Goniewicz, M. L. et al. Comparison of Nicotine and Toxicant Exposure in Users of Electronic Cigarettes and Combustible Cigarettes. JAMA Netw Open, 1, e185937 https://doi.org/doi:10.1001/jamanetworkopen.2018.5937 (2018).

7. Hecht, S. S. et al. Evaluation of toxicant and carcinogen metabolites in the urine of e-cigarette users versus cigarette smokers. Nicotine Tob Res, 17, 704-709 https://doi.org/doi:10.1093/ntr/ntu218 (2015).

8. Round, E. K., Chen, P., Taylor, A. K. \& Schmidt, E. Biomarkers of Tobacco Exposure Decrease After Smokers Switch to an E-Cigarette or Nicotine Gum. Nicotine Tob Res, 21, 1239-1247 https://doi.org/doi:10.1093/ntr/nty140 (2019). 
9. Shahab, L. et al. Nicotine, Carcinogen, and Toxin Exposure in Long-Term E-Cigarette and Nicotine Replacement Therapy Users: A Cross-sectional Study. Ann Intern Med, 166, 390-400 https://doi.org/doi:10.7326/M16-1107 (2017).

10. England., P. H. (2015)

11. Physicians, R. C. (ed) o(Suffolk, England, 2016)

12. Eaton, D. L., Kwan, L. Y. \& Stratton, K. (eds) in Public Health Consequences of E-Cigarettes (eds, \&) (2018)

13. Campbell, C. et al. Part One: Abuse Liability of Vise Solo Relative to Combustible Cigarettes and Nicotine Gum. (In preparation.).

14. Kanobe, M. N. et al. Part Three: Biomarker Changes in Cigarette Smokers Switched to Vuse Solo or Abstinence. (In progress).

15. Stiles, M. F. et al. Pharmacodynamic and pharmacokinetic assessment of electronic cigarettes, combustible cigarettes, and nicotine gum: implications for abuse liability., 234, 2643-2655 https://doi.org/doi:10.1007/s00213-017-4665-y (2017).

16. Stiles, M. F. et al. Assessment of the abuse liability of three menthol Vuse Solo electronic cigarettes relative to combustible cigarettes and nicotine gum., 235, 2077-2086 https://doi.org/doi:10.1007/s00213-018-4904-x (2018).

17. Hajek, P., Przulj, D., Phillips, A., Anderson, R. \& McRobbie, H. Nicotine delivery to users from cigarettes and from different types of e-cigarettes., 234, 773-779 https://doi.org/doi:10.1007/s00213-0164512-6 (2017).

18. Goldenson, N. I., Buchhalter, A. R., Augustson, E. M., Rubinstein, M. L. \& Henningfield, J. E. Abuse liability assessment of the JUUL system in four flavors relative to combustible cigarette, nicotine gum and a comparator electronic nicotine delivery system among adult smokers. Drug Alcohol Depend, 217, 108395 https://doi.org/doi:10.1016/j.drugalcdep.2020.108395 (2020).

19. Farsalinos, K. E. et al. Nicotine absorption from electronic cigarette use: comparison between experienced consumers (vapers) and naive users (smokers). Sci Rep, 5, 11269 https://doi.org/doi:10.1038/srep11269 (2015).

20. Farsalinos, K. E. et al. Nicotine absorption from electronic cigarette use: comparison between first and new-generation devices. Sci Rep, 4, 4133 https://doi.org/doi:10.1038/srep04133 (2014).

21. Fearon, I. M. et al. E-cigarette Nicotine Delivery: Data and Learnings from Pharmacokinetic Studies. Am J Health Behav, 41, 16-32 https://doi.org/doi:10.5993/ajhb.41.1.2 (2017).

22. Vansickel, A. R. \& Eissenberg, T. Electronic cigarettes: effective nicotine delivery after acute administration. Nicotine Tob Res, 15, 267-270 https://doi.org/doi:10.1093/ntr/ntr316 (2013).

23. St Helen, G., Havel, C., Dempsey, D. A., Jacob, P., Benowitz, N. L. \& 3rd \& Nicotine delivery, retention and pharmacokinetics from various electronic cigarettes., 111, 535-544 https://doi.org/doi:10.1111/add.13183 (2016). 
24. St Helen, G. et al. Differences in nicotine intake and effects from electronic and combustible cigarettes among dual users., 115, 757-767 https://doi.org/doi:10.1111/add.14884 (2020).

25. Yingst, J. M. et al. Nicotine Absorption Profile Among Regular Users of a Pod-Based Electronic Nicotine Delivery System. JAMA Netw Open, 2, e1915494 https://doi.org/doi:10.1001/jamanetworkopen.2019.15494 (2019).

26. St Helen, G., Dempsey, D. A., Havel, C. M., Jacob, P., Benowitz, N. L. \& 3rd \& Impact of e-liquid flavors on nicotine intake and pharmacology of e-cigarettes. Drug Alcohol Depend, 178, 391-398 https://doi.org/doi:10.1016/j.drugalcdep.2017.05.042 (2017).

27. St Helen, G., Shahid, M., Chu, S. \& Benowitz, N. L. Impact of e-liquid flavors on e-cigarette vaping behavior. Drug Alcohol Depend, 189, 42-48 https://doi.org/doi:10.1016/j.drugalcdep.2018.04.032 (2018).

28. Voos, N. et al. Effect of e-cigarette flavors on nicotine delivery and puffing topography: results from a randomized clinical trial of daily smokers., 237, 491-502 https://doi.org/doi:10.1007/s00213-01905386-x (2020).

29. Cobb, C. O. et al. Influence of electronic cigarette liquid flavors and nicotine concentration on subjective measures of abuse liability in young adult cigarette smokers. Drug Alcohol Depend, 203, 27-34 https://doi.org/doi:10.1016/j.drugalcdep.2019.05.024 (2019).

30. Marsot, A. \& Simon, N. Nicotine and Cotinine Levels With Electronic Cigarette: A Review. Int J Toxicol, 35, 179-185 https://doi.org/doi:10.1177/1091581815618935 (2016).

31. Walele, T., Sharma, G., Savioz, R., Martin, C. \& Williams, J. A randomised, crossover study on an electronic vapour product, a nicotine inhalator and a conventional cigarette. Part A:

Pharmacokinetics. Regul Toxicol Pharmacol, 74, 187-192

https://doi.org/doi:10.1016/j.yrtph.2015.12.003 (2016).

32. Dawkins, L. E., Kimber, C. F., Doig, M., Feyerabend, C. \& Corcoran, O. Self-titration by experienced ecigarette users: blood nicotine delivery and subjective effects., 233, 2933-2941 https://doi.org/doi:10.1007/s00213-016-4338-2 (2016).

33. Voos, N. et al. Randomized within-subject trial to evaluate smokers' initial perceptions, subjective effects and nicotine delivery across six vaporized nicotine products., 114, 1236-1248 https://doi.org/doi:10.1111/add.14602 (2019).

34. Yingst, J. M. et al. Nicotine absorption during electronic cigarette use among regular users. PLoS One, 14, e0220300 https://doi.org/doi:10.1371/journal.pone.0220300 (2019).

35. Benowitz, N. L., Swan, G. E., Jacob, P. 3, Lessov-Schlaggar, C. N., Tyndale, R. F. \& rd, \& CYP2A6 genotype and the metabolism and disposition kinetics of nicotine. Clin Pharmacol Ther, 80, 457-467 https://doi.org/doi:10.1016/j.clpt.2006.08.011 (2006).

36. Breland, A. B., Kleykamp, B. A. \& Eissenberg, T. Clinical laboratory evaluation of potential reduced exposure products for smokers. Nicotine Tob Res, 8, 727-738 https://doi.org/doi:10.1080/14622200600789585 (2006). 
37. Bullen, C. et al. Effect of an electronic nicotine delivery device (e cigarette) on desire to smoke and withdrawal, user preferences and nicotine delivery: randomised cross-over trial. Tob Control, 19, 98 103 https://doi.org/doi:10.1136/tc.2009.031567 (2010).

38. Dawkins, L. \& Corcoran, O. Acute electronic cigarette use: nicotine delivery and subjective effects in regular users., 231, 401-407 https://doi.org/doi:10.1007/s00213-013-3249-8 (2014).

39. Eissenberg, T. Electronic nicotine delivery devices: ineffective nicotine delivery and craving suppression after acute administration. Tob Control, 19, 87-88 https://doi.org/doi:10.1136/tc.2009.033498 (2010).

40. O'Connell, G. et al. A randomised, open-label, cross-over clinical study to evaluate the pharmacokinetic profiles of cigarettes and e-cigarettes with nicotine salt formulations in US adult smokers. Intern Emerg Med, 14, 853-861 https://doi.org/doi:10.1007/s11739-019-02025-3 (2019).

41. Ramoa, C. P. et al. Electronic cigarette nicotine delivery can exceed that of combustible cigarettes: a preliminary report. Tob Control, 25, e6-9 https://doi.org/doi:10.1136/tobaccocontrol-2015-052447 (2016).

42. Vansickel, A. R., Cobb, C. O., Weaver, M. F. \& Eissenberg, T. E. A clinical laboratory model for evaluating the acute effects of electronic "cigarettes": nicotine delivery profile and cardiovascular and subjective effects. Cancer Epidemiol Biomarkers Prev, 19, 1945-1953 https://doi.org/doi:10.1158/1055-9965.EPI-10-0288 (2010).

43. Shiffman, S., Ferguson, S. G. \& Strahs, K. R. Quitting by gradual smoking reduction using nicotine gum: a randomized controlled trial. Am J Prev Med 36, 96-104 e101, doi:10.1016/j.amepre.2008.09.039 (2009)

44. St Helen, G. et al. Nicotine Delivery and Vaping Behavior During ad Libitum E-cigarette Access. Tob Regul Sci, 2, 363-376 https://doi.org/doi:10.18001/TRS.2.4.8 (2016).

45. Benowitz, N. L., Hukkanen, J., Jacob, P. 3 \& rd. Nicotine chemistry, metabolism, kinetics and biomarkers. Handb Exp Pharmacol, 29-60 https://doi.org/doi:10.1007/978-3-540-69248-5_2 (2009).

\section{Figures}




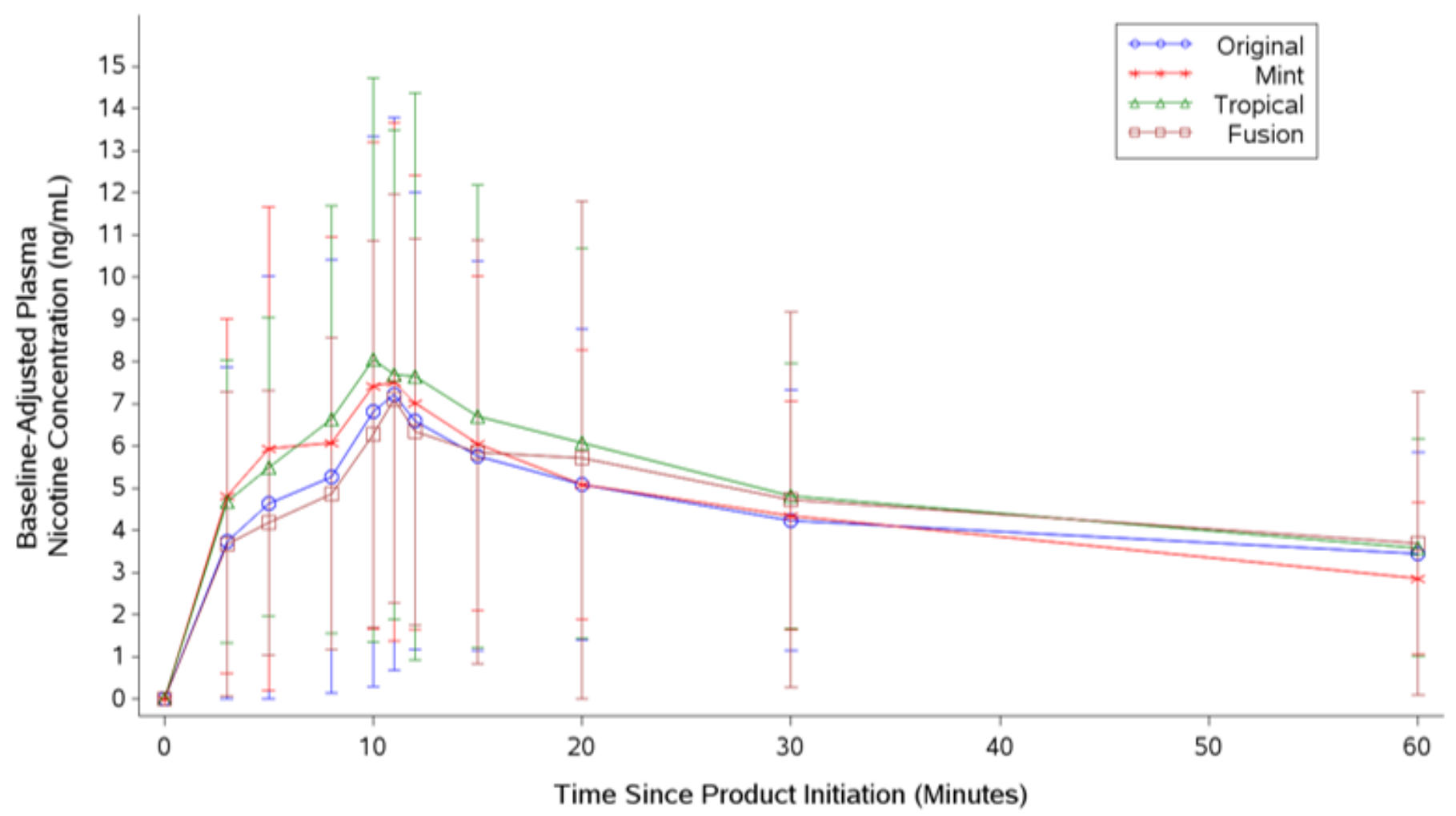

Figure 1

Baseline-Adjusted Plot of Arithmetic Mean Plasma Nicotine Concentrations (0-60 minutes) for Four Flavor Variants of Vuse Solo 


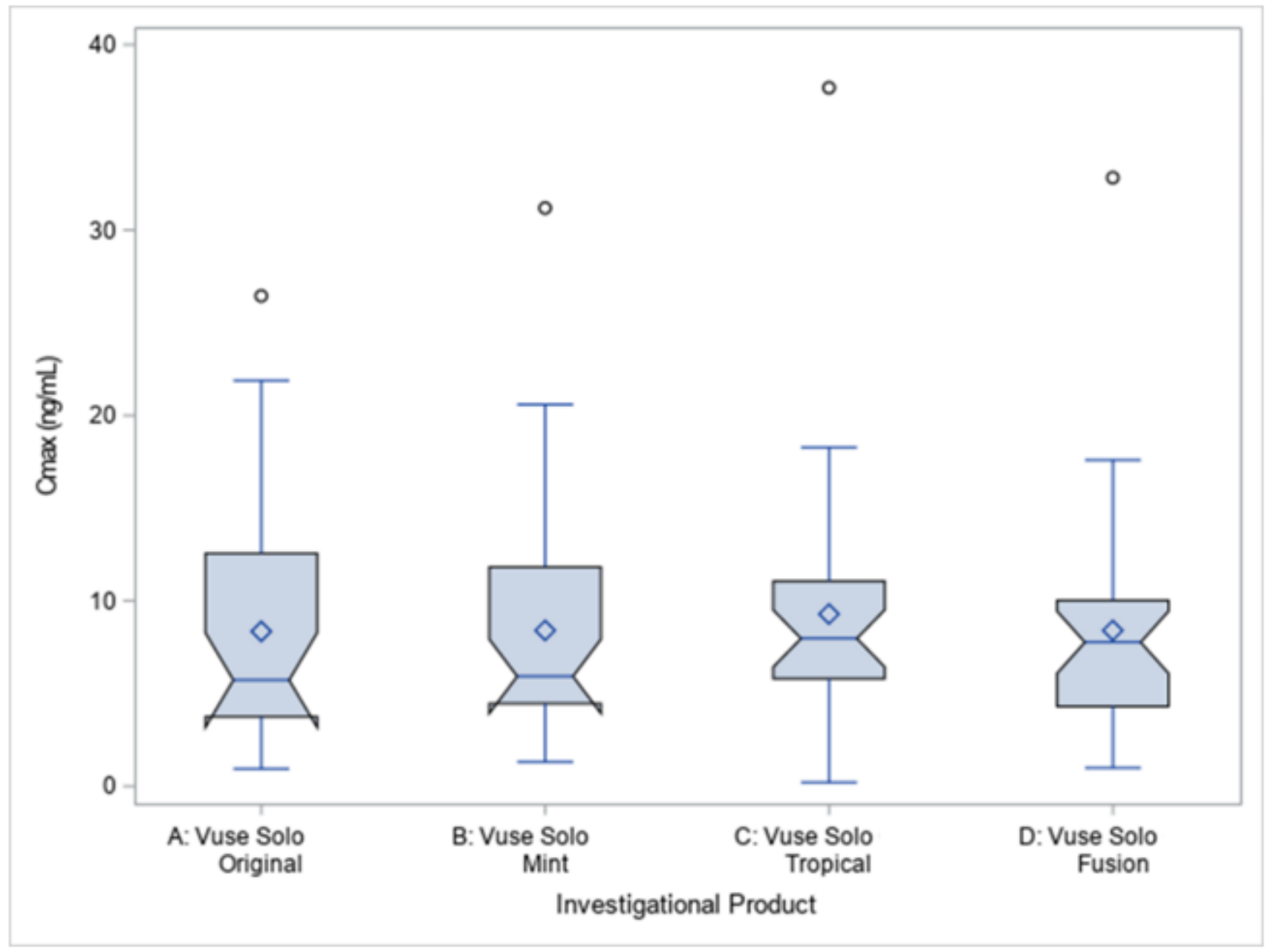

Figure 2

Notched Box Plot of Baseline-Adjusted Cmax for Four Flavor Variants of Vuse Solo 


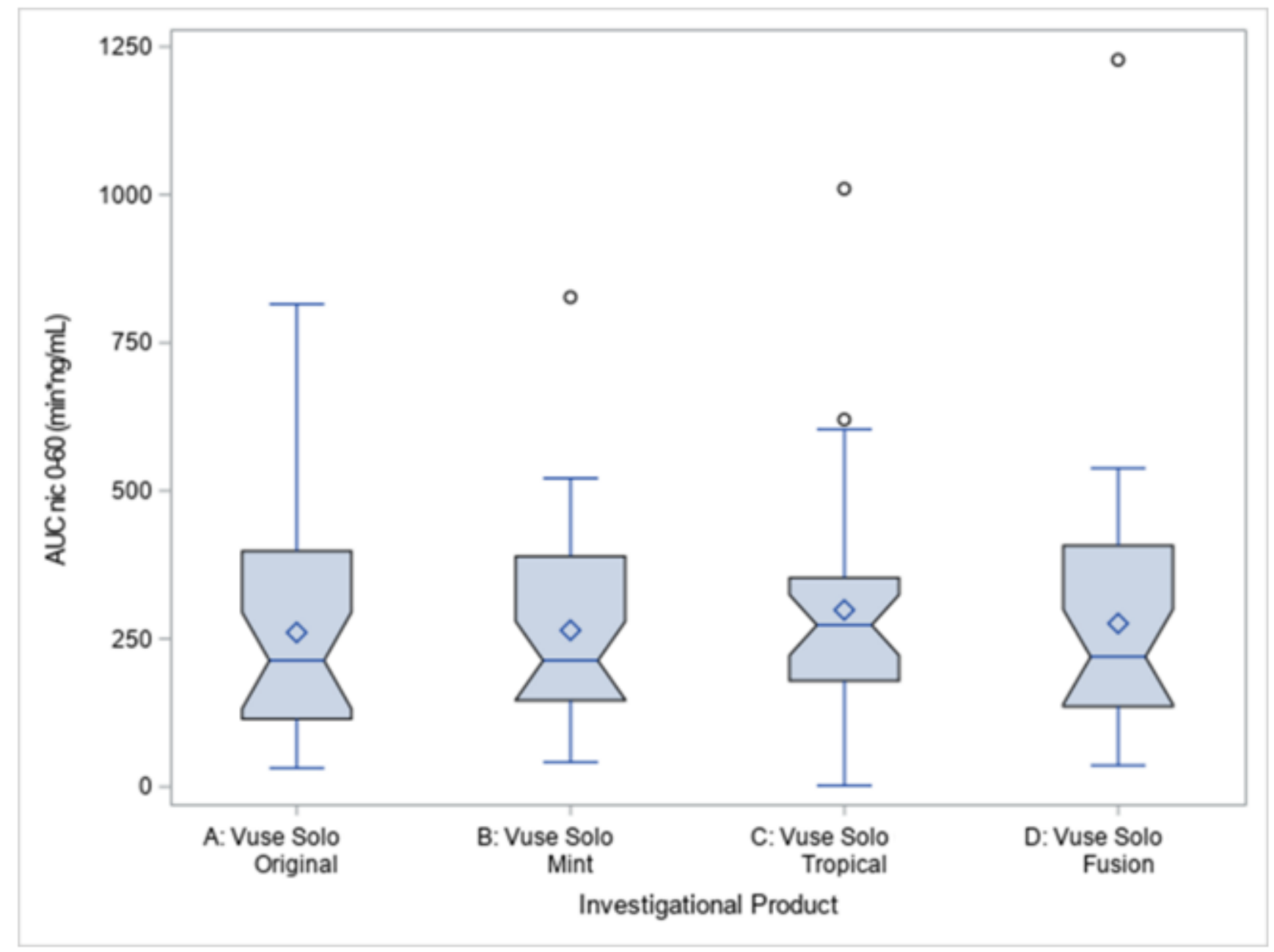

Figure 3

Notched Box Plot of Baseline-Adjusted AUCnic0-60 for Four Flavor Variants of Vuse Solo

\section{Supplementary Files}

This is a list of supplementary files associated with this preprint. Click to download.

- VuseSoloPKManuscriptSupplementaryTables.docx 